Forsythe, J. M., S. Q. Kidder, K. K. Fuell, A. LeRoy, G. J. Jedlovec, and A. S. Jones, 2015: A multisensor, blended, layered water vapor product for weather analysis and forecasting. J. Operational Meteor., 3 (5), 41-58, doi: http://dx.doi.org/10.15191/nwajom.2015.0305.

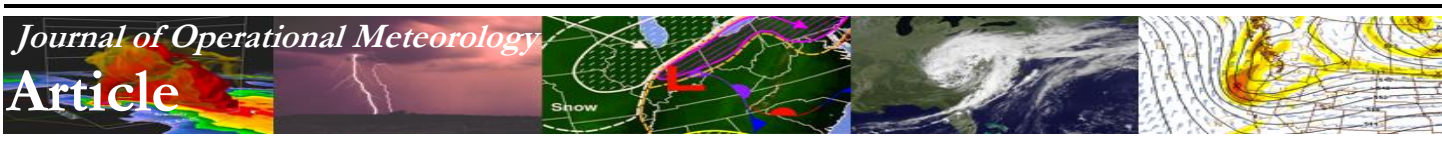

\title{
A Multisensor, Blended, Layered Water Vapor Product for Weather Analysis and Forecasting
}

\author{
JOHN M. FORSYTHE and STANLEY Q. KIDDER \\ Cooperative Institute for Research in the Atmosphere, Colorado State University, Fort Collins, Colorado \\ KEVIN K. FUELL and ANITA LEROY \\ University of Alabama Huntsville, Huntsville, Alabama \\ GARY J. JEDLOVEC \\ NASA Short-term Prediction Research and Transition Center, Huntsville, Alabama \\ ANDREW S. JONES \\ Cooperative Institute for Research in the Atmosphere, Colorado State University, Fort Collins, Colorado
}

(Manuscript received 20 August 2014; review completed 4 February 2015)

\begin{abstract}
This paper describes the creation of a near real-time, near-global, four-layer (surface-850, 850-700, 700500, and 500-300 hPa) blended layered water vapor (LWV) product using retrieved soundings from five polar-orbiting satellites [National Oceanic and Atmospheric Administration (NOAA)-18 and NOAA-19 satellites; Defense Meteorological Satellite Program F-18 satellite; Meteorological Operational satellite program's Metop-A satellite; and National Atmospheric and Space Administration (NASA) Aqua satellite]. Both layer precipitable water (LPW) and layer relative humidity (LRH) are included in the blended LWV product. The NASA Atmospheric Infrared Sounder Version 6 retrieval product and NOAA Microwave Integrated Retrieval System soundings are used to create the product, and the use of retrieved water vapor profiles from multiple satellite inputs at different local times allows visualization of the flow of water vapor in layers. The product has advantages and complements geostationary water vapor imagery, derived products from geostationary satellites, and radiosondes in tracking moisture over data sparse regions in cloudy conditions. LPW profiles show absolute values at each layer of the column, while LRH profiles give a sense of whether the column is moistening or drying with height. Examples of the product are given for a severe weather case, the September 2013 Colorado Front Range floods, and a landfalling tropical depression. The usefulness of the product is discussed from the perspective of how tools commonly used by forecasters to analyze water vapor are augmented by the blended layered water vapor fields.
\end{abstract}

\section{Introduction}

Analyzing the distribution of water vapor from observations is a key component of the forecast cycle. Both integrated (e.g., total precipitable water, TPW) and vertically resolved moisture fields are necessary, depending on the particular forecast challenge. Typically, National Weather Service (NWS) forecasters rely on a few standard tools for this task. These include radiosondes, blended TPW from many satellites and surface observations, GOES water vapor imagery, and GOES sounder imagery. These tools, and their characteristics are summarized in Table 1 .
However, currently no observing systems within the NWS region of responsibility provide moisture soundings for weather forecasting that are available hourly with good vertical resolution and can be obtained over land or ocean under clear or cloudy skies. A 4-D water vapor product can be applied to many forecasting problems. It can be used to assess the depth of an atmospheric river to determine how much moisture will make it over coastal mountains, such as the Cascades. Data indicating a hostile or favorable midlevel moisture environment around a tropical wave can be used to help predict whether 
Table 1. Characteristics of moisture products commonly used by forecasters.

\begin{tabular}{|l|l|l|l|l|}
\hline Moisture Product & $\begin{array}{l}\text { Spatial Resolution } \\
\text { and Coverage }\end{array}$ & $\begin{array}{l}\text { Temporal } \\
\text { Resolution }\end{array}$ & Strengths & Limitations \\
\hline Radiosondes & $\begin{array}{l}\sim 500 \mathrm{~km} \text { over the } \\
\text { CONUS; none over } \\
\text { the ocean }\end{array}$ & $12 \mathrm{~h}$ & Trusted; high vertical resolution & Spatial and temporal coverage \\
\hline $\begin{array}{l}\text { GOES Water Vapor } \\
\text { Channel }(6.7 \mu \mathrm{\mu m}) \\
\text { Imagery }\end{array}$ & $\begin{array}{l}4 \mathrm{~km}, \text { near- } \\
\text { hemispheric } \\
\text { coverage }\end{array}$ & 15 min or less & $\begin{array}{l}\text { Very high spatial and temporal } \\
\text { resolution; animations show flow }\end{array}$ & $\begin{array}{l}\text { Upper-level moisture only; no } \\
\text { vapor signal in high clouds; } \\
\text { variable sensing depth }\end{array}$ \\
\hline $\begin{array}{l}\text { GOES Sounder } \\
\text { Retrievals }\end{array}$ & $\begin{array}{l}\text { Hawaii, Puerto } \\
\text { Rico, and adjacent } \\
\text { waters only }\end{array}$ & $1 \mathrm{~h}$ & $\begin{array}{l}\text { High spatial and temporal } \\
\text { resolution; limited vertical } \\
\text { structure }\end{array}$ & $\begin{array}{l}\text { Clear sky only; forecast model } \\
\text { dependence }\end{array}$ \\
\hline Blended TPW & $\begin{array}{l}16 \mathrm{~km}, \text { near global } \\
\text { on time of day) }\end{array}$ & $\begin{array}{l}\text { Retrievals in clouds; near-global } \\
\text { coverage; multiple types of inputs } \\
\text { including very accurate GPS TPW }\end{array}$ & $\begin{array}{l}\text { No profile information; no } \\
\text { retrievals in heavy precipitation }\end{array}$ \\
\hline
\end{tabular}

tropical cyclone genesis is likely. Upper-level moisture above $500 \mathrm{hPa}$ can be useful to predict whether cirrus clouds will form or persist and impact high or low temperature forecasts. A 4-D water vapor field can be assimilated by a forecast model to yield positive impacts on convective forecasts as shown by the assimilation of single-swath satellite moisture data (Jones and Stensrud 2012). Moisture fields can serve as a feature map in order to reduce model displacement errors (e.g., Nehrkorn et al. 2014). Therefore, a multisensor technique to exploit advances in satellite remote sensing to improve the depiction of water vapor was developed and is presented here.

In order to improve data transition from National Air and Space Administration (NASA) research satellites, NASA's Short-term Prediction Research and Transition (SPoRT) Center was formed in 2002. SPoRT has expertise on transitioning unique NASA datasets that might be unfamiliar to forecasters but can provide value in weather forecasting and analysis. Some examples are very high spatial and spectral resolution imagery from the Moderate Resolution Imaging Spectroradiometer (MODIS), hyperspectral soundings from NASA Atmospheric Infrared Sounder (AIRS), and ground-based lightning mapping networks. Some current research and transition activities at SPoRT aim to increase the utility of the Suomi National Polar-orbiting Partnership (NPP) and Joint Polar Satellite System missions within the operational weather community.

Characteristics of commonly used water vapor products are summarized in Table 1. Forecasters use these tools to compare model depictions of moisture with observations. All of these observations have particular strengths and weaknesses that influence their application. Radiosondes provide good vertical structure at a point but are infrequent in time, fail to capture mesoscale moisture structure, and over oceans are limited to a few islands. Infrared water vapor imagery has temporal resolution of a few minutes and can be animated to capture atmospheric motion, but high clouds can mask lower-level water vapor features. In addition it is sensitive only to the first 1-2 $\mathrm{mm}$ of moisture in cloud-free regions at a level of the atmosphere that varies according to the moisture amount (Jedlovec et al. 2000). Because the global average TPW is about $25 \mathrm{~mm}$ (Vonder Haar et al. 2012), this is typically upper-level moisture except with extremely dry atmospheres. The Geostationary Operational Environmental Satellite (GOES) sounder provides three broad layers of precipitable water but only in clear regions and over limited hourly sectors near the contiguous United States (CONUS) and coastal waters, as well as less frequent sectors over Hawaii and the Caribbean. In addition, the GOES sounder is dependent on first-guess information from the Global Forecast System (GFS) model to constrain the solution, which makes comparison to model forecasts more challenging. Also, a retrieval system that depends heavily on the model for its water vapor solution can be ambiguous and less useful for forecasters. Of the moisture products listed in Table 1, only the GOES sounder has a dynamic forecast model dependency directly linked to current model water vapor fields. A satellite sounder is not on the manifest for the next generation of GOES satellites (GOES-R series), but legacy atmospheric profiles will be derived from the $G O E S-R /-S$ Advanced Baseline Imager (Lee 
et al. 2014) with three channels particularly sensitive to water vapor. The expected performance of the legacy atmospheric moisture profile from the imager is on the order of the current sounder performance and better than the $18 \%$ accuracy specification for this product ( $\mathrm{Li}$ et al. 2010). The GOES-R/S legacy atmospheric profiles will have excellent time and spatial resolution but will only be possible in cloudfree regions within the satellite field-of-view. Although the new layered precipitable water product presented here has coarser temporal and spatial resolution and more latency, it delivers profiles in cloudy conditions over the entire globe except in polar regions. The widespread use of the blended TPW since becoming operational in 2009 provided a natural impetus to develop and explore the forecast utility of a vertically resolved product with similar temporal and spatial resolution (Table 1). The new product is not a replacement for blended TPW, which uses other data sources besides those discussed here.

The operational National Oceanic and Atmospheric Administration (NOAA) Blended TPW product (Forsythe et al. 2012) does not have vertical information on the moisture distribution, but it is derived from passive microwave moisture soundings in all conditions except heavy precipitation and snow/ice covered surfaces. A new blended layered water vapor (LWV) product containing layer precipitable water (LPW) and layer relative humidity (LRH) was created from satellite water vapor soundings. Blended LWV refers to both products, although blended LPW and blended LRH are standalone products. The new product is not limited to land and is especially valuable over oceans where radiosondes are not launched. Gradients of moisture in layers are readily visualized with the new product, and the product can be compared to forecast models as an independent estimate of model performance. In section 2 , the satellite inputs to the blended product are detailed. Section 3 describes the construction of the mapped blended product. Examples of the product are presented in section 4. Conclusions and suggestions for further evolution of the product are presented in section 5 .

\section{Satellite moisture profile data}

To improve upon the limitations of common moisture products listed in Table 1 and to address problems such as the void in current instrumentation in capturing both vertical profile and spatial structure, the
Cooperative Institute for Research in the Atmosphere (CIRA) developed a blended LWV product using polar-orbiting satellites. The result is a product very similar to the NOAA operational blended TPW and anomaly products (Kidder and Jones 2007; Forsythe et al. 2012; www.ospo.noaa.gov/Products/bTPW/index.html). The blended LWV product suite is a composite of water vapor retrievals for multiple layers using infrared and microwave sensors on polar-orbiting satellites that are mapped to a $16-\mathrm{km}$ Mercator grid, in common with the blended TPW and anomaly grid. The use of microwave data provides an advantage over infrared soundings that need a cloud-free view to sense low-level moisture. Two types of moisture profile retrievals are blended: the NOAA Microwave Integrated Retrieval System (MIRS; Boukabara et al. 2011) soundings and AIRS soundings (Dang et al. 2012; Olsen 2013). AIRS is used in mostly cloud-free regions and over snow-covered surfaces where MIRS retrievals are not used because of complex surface emissivity. The blended LWV product fills the gaps left by traditional point observations, which are not included in the version described in this paper. Blended LWV uses a subset of the satellite data used in the blended TPW product, except for AIRS which is used only in blended LWV.

Some expected impacts to forecast operations of the blended LWV product are shown in Table 2. It is anticipated that blended LWV will assist forecasters in a similar manner as the blended TPW product. Both products have the strength of depicting the moisture field over data-sparse oceans, so it is expected that coastal forecast offices might particularly benefit from blended LWV. As with blended TPW, comparison to forecast models is possible with blended LWV. Although current operational models do not carry the integrated layers, a comparison to forecast models is possible once they are derived from model output. While blended LWV is termed a near real-time product, latencies of 2-4 h are common because of delays in receipt, processing, and distribution of polarorbiting satellite data. Such latencies make the blended LWV less applicable to mesoscale meteorology and nowcasting, but for synoptic analyses they should not inhibit depiction of the atmospheric moisture state.

The design of the blended LWV product draws upon experience and feedback gathered over five years as team members on the NOAA operational blended TPW and rain rate products. Forecasters desire blended products that are consistent through time so that moisture features can be tracked. Therefore, 
Table 2. Examples where the blended layered water vapor product could impact operations.

\begin{tabular}{|l|l|}
\hline Feature & Potential Impact to Operations \\
\hline Vertical Profile of Moisture & $\begin{array}{l}\text { The blended LPW and LRH can be used to examine and understand the moisture depth in the atmosphere. This could } \\
\text { be useful when analyzing atmospheric rivers or to determine moisture transport across a topographic barrier, such as } \\
\text { the Cascade Range. GOES 6.7- } \mu \mathrm{m} \text { and blended TPW do not show the vertical distribution of moisture. }\end{array}$ \\
\hline $\begin{array}{l}\text { Coverage over Data-Void } \\
\text { Areas }\end{array}$ & $\begin{array}{l}\text { The LPW provides some vertical structure of moisture over data-void ocean regions and over land in regions between } \\
\text { the radiosonde network. }\end{array}$ \\
\hline $\begin{array}{l}\text { Visualization of Horizontal } \\
\text { Gradients in Layers }\end{array}$ & $\begin{array}{l}\text { A primary use of the LPW and LRH is to show gradients in water vapor within individual layers, which are poorly } \\
\text { diagnosed from radiosondes (or not at all over ocean). Moisture gradients around Atlantic tropical cyclones may be } \\
\text { predictive of intensification (Wu et al. 2012). }\end{array}$ \\
\hline $\begin{array}{l}\text { Independent Comparison to } \\
\text { Forecast Models }\end{array}$ & $\begin{array}{l}\text { Forecast models currently assimilate much less satellite moisture information than is contained in the LPW retrievals, } \\
\text { so comparisons between the LPW and LRH products and model forecasts can be performed. Both the MIRS and } \\
\text { AIRS retrievals are not dependent on dynamical forecast model inputs for moisture information. }\end{array}$ \\
\hline
\end{tabular}

missing data should be minimized, as that makes it difficult to track the flow of moisture. In the end, the retrievals from the different satellite systems must exhibit visual consistency between moisture features, both spatially and in time, for forecasters to include them in their operations.

The requirement for spatial and temporal consistency is an additional and challenging metric placed on the blended LWV product beyond the typical validation of a retrieval algorithm that involves a comparison to radiosonde data, a numerical model analysis, or ground-based measurements. Inter-satellite retrieval biases must be small, or they may be interpreted by a forecaster as unrealistic moistening or drying. The blended LWV product must flow seamlessly through time and not introduce artifacts, such as satellite swath boundaries that a forecaster might interpret to be a meaningful meteorological feature. They must not show erratic time behavior, such as moisture pulsing up and down at a point or features becoming thinner or wider as they are observed by different satellites. The visual quality of the blended LPW and LRH product, while difficult to quantify, serves as a comprehensive test of all input components of the system. If the blended LWV products do not pass these tests they are unlikely to be accepted by forecasters.

At CIRA, a system called DPEAS (the Data Processing and Error Analysis System; Jones and Vonder Haar 2002) has been developed. DPEAS makes it relatively easy to ingest common data formats (e.g., HDF-EOS, HDF5, netCDF), reproject the data to a common grid, composite independent instances of the data, and blend and intercalibrate data from different platforms into one or several products.
Individual swaths of each satellite are mapped onto the desired map projection using bilinear interpolation and accounting for missing scan lines. Inter-calibration or bias correction is not performed for this first version of blended LWV. For blended TPW, one satellite is chosen as the reference standard, and running five-day ocean histograms of TPW from every other satellite are matched to the reference. For the initial development of blended LWV presented here, histogram matching is not used in order to better visualize the performance of each sensor input. DPEAS is the engine that runs the NOAA operational Blended TPW and anomaly products and Blended Rain Rate products (Kidder and Jones 2007), and it is used to produce the blended LWV products.

Five polar-orbiting spacecraft are currently included in the blended LWV product: NOAA-18 and -19; Defense Meteorological Satellite Program (DMSP) F-18; the Meteorological Operational (Metop) satellite program's Metop-A; and NASA Aqua. These spacecraft are in a sun-synchronous orbit (Kidder and Vonder Haar 1995) and sample at the same local time of day, $12 \mathrm{~h}$ apart with local equator crossing times for the spacecraft provided in Fig. 1. It is important to note that the spacecraft are not equally spaced in local time (Fig. 1). In fact, NOAA-19 and Aqua currently have almost identical ascending node times of 1330 and 1338 local time and a nearly 5-h gap exists between the NOAA-18 and DMSP F-18 overpasses, from 1516 to 2001 local time. This means that there are periods of good temporal refresh and spatial coverage between 1330 and 1530 local time and periods of a few hours when no new data is available at a given location. This causes portions of 


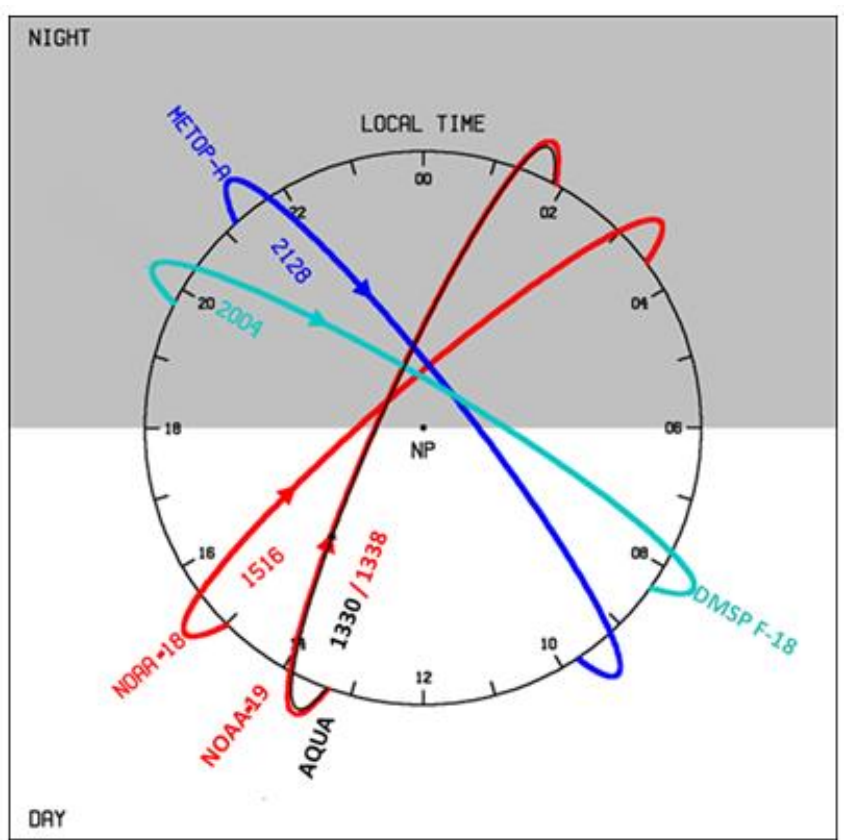

Figure 1. Local ascending node equator crossing times for satellites (Metop-A, DMSP F-18, NOAA-18, NOAA-19, and Aqua) currently contributing to the LPW product. Note that NOAA-19 and Aqua passes are at a nearly coincident time, and descending node times are $12 \mathrm{~h}$ after the ascending node times. Click image for an external version; this applies to all figures hereafter.

the blended LWV products to remain stationary in an animation because a new image is created every $3 \mathrm{~h}$.

The satellite sounding systems used in blended LPW and blended LRH are now described.

\section{a. Atmospheric Infrared Sounder (AIRS)}

On the NASA Aqua spacecraft, which has been operating since 2002, AIRS and the Advanced Microwave Sounding Unit-A (AMSU-A) instrument retrieve profiles of temperature, moisture, and other trace gases. AIRS is a hyperspectral instrument and can potentially retrieve more unique vertical information than broadband infrared sounders, such as onboard GOES or the High Resolution Infrared Sounder on the NOAA and Metop spacecraft.

In March 2013, AIRS Version 6 retrievals became available (Dang et al. 2012) and are the science results are presented in this paper. Version 6 has several science improvements, including the fraction of useful retrievals (yield) that is significantly higher in the troposphere for good quality retrievals. The AIRS sounding product also allows a user to distinguish between "Good" and "Best" retrievals, which are primarily affected by the presence and height of cloud tops in the field-of-view. For example, "Good" retrievals are possible in the presence of clouds, particularly low clouds, and represent a wider range of weather conditions. The quality control of "Best" retrievals is stricter, and these are suitable for data assimilation studies. In Version 6 the highest pressure, that is to say the nearest AIRS pressure level to the surface, down to which a sounding is useable is indicated by the variable $\mathrm{P}_{\text {Good }}$ or $\mathrm{P}_{\text {Best }}$, with $\mathrm{P}_{\text {Good }} \geq \mathrm{P}_{\text {Best }}$. In order to maximize spatial coverage of the AIRS data in the blended LWV product, retrievals with $\mathrm{P}_{\text {Good }}$ are used in this work. The AIRS retrieval uses a dynamic surface pressure from the NASA GEOS-5 model.

AIRS retrieval products are acquired in near realtime from the NASA Land, Atmosphere Near realtime Capability for EOS (LANCE) system, and the typical latency between observation and file receipt at CIRA is about 2-3 h. The HDF-EOS files from LANCE are read into DPEAS, and a translator assembles the original 12 moisture layers from the surface to the lowest pressure layer reported into the layers selected for the blended LWV products. Finally, remapping onto the $16-\mathrm{km}$ Mercator projection is performed for each 6-min granule and, at this time, the AIRS retrievals are then ready to join the blended LWV products.

\section{b. Microwave Integrated Retrieval System (MIRS)}

CIRA also ingests the MIRS sounding product (Boukabara et al. 2011), Version 8.0, in near real-time from the NOAA Data Distribution Server (DDS) system for inclusion in the blended LWV products. Currently, MIRS sounding retrievals are available from the NOAA-18, NOAA-19, Metop-A, Metop-B, and DMSP F-18 satellites. The primary source of water vapor profile information on these spacecraft is from a set of channels near the water vapor absorption line at $183 \mathrm{GHz}$. The particular instruments making these measurements are the Microwave Humidity Sounder (MHS) on the NOAA and Metop spacecraft and the Special Sensor Microwave Imager/Sounder (SSM/IS) on DMSP.

The spatial resolutions of the MIRS soundings vary according to sensor. NOAA-18, -19 and Metop-A retrievals are produced at the AMSU-A sensor resolution, $48 \mathrm{~km}$ at nadir with resolution decreasing by a factor of two across the 30 -element scan line. The MIRS soundings from DMSP are produced at the resolution of the upper atmospheric sounding 
channels, which is approximately $75 \mathrm{~km}$. Boukabara et al. (2011) give details on the MIRS resolution and footprint matching. Currently, MIRS is being used to perform retrievals at a spatial resolution of $16 \mathrm{~km}$ at nadir from the Suomi-NPP and Metop-B satellites. The SSM/IS instrument on DMSP F-18 is a conical scanner (constant spatial resolution), while the AMSU, MHS, and AIRS instruments perform a cross-track scan with maximum spatial resolution at nadir.

In a similar approach as AIRS, the MIRS retrievals are ingested into DPEAS and then quality controlled with the MIRS quality control flags. In particular, precipitating retrievals and any retrievals marked as bad are rejected, and this leads to missing data over precipitating regions. MIRS retrievals use a static surface pressure based on topography, so there is no forecast model dependence in the MIRS retrieval. The granules (individual orbits for MIRS) are remapped to the output grid projection and are ready to join the blended LWV products.

\section{c. Accuracy and vertical resolution of AIRS and MIRS products}

In order for forecasters to understand and use the blended LWV products, some knowledge of the vertical resolution and uncertainty of the product inputs is needed. Satellite soundings from AIRS and the MIRS system are fundamentally different than radiosondes. Whereas radiosondes measure moisture at various levels in the atmosphere, satellite moisture soundings from the AIRS and MIRS systems are best interpreted as representing broad layers of the atmosphere. This is because the channels on each spacecraft measure radiances, which originate from a great depth of the atmosphere. This concept can be visualized by means of a weighting function (Kidder and Vonder Haar 1995). The weighting functions for the five MHS microwave channel frequencies are shown in Fig. 2. The $89 \mathrm{GHz}$ channel senses mostly emission from the land with some contribution from the lower troposphere, while the $183 \pm 1 \mathrm{GHz}$ and 183 $\pm 3 \mathrm{GHz}$ channels respond mainly to moisture near 400 and $600 \mathrm{hPa}$ respectively with little sensitivity to moisture near the surface.

The optimal estimation retrieval framework used in the AIRS and MIRS retrieval (Rodgers 2000) provide diagnostics, such as the number of degrees of freedom or independent pieces of vertical information and impact of the observations on the solution. An optimal estimation retrieval solution can be viewed as a compromise between the impact of the observations

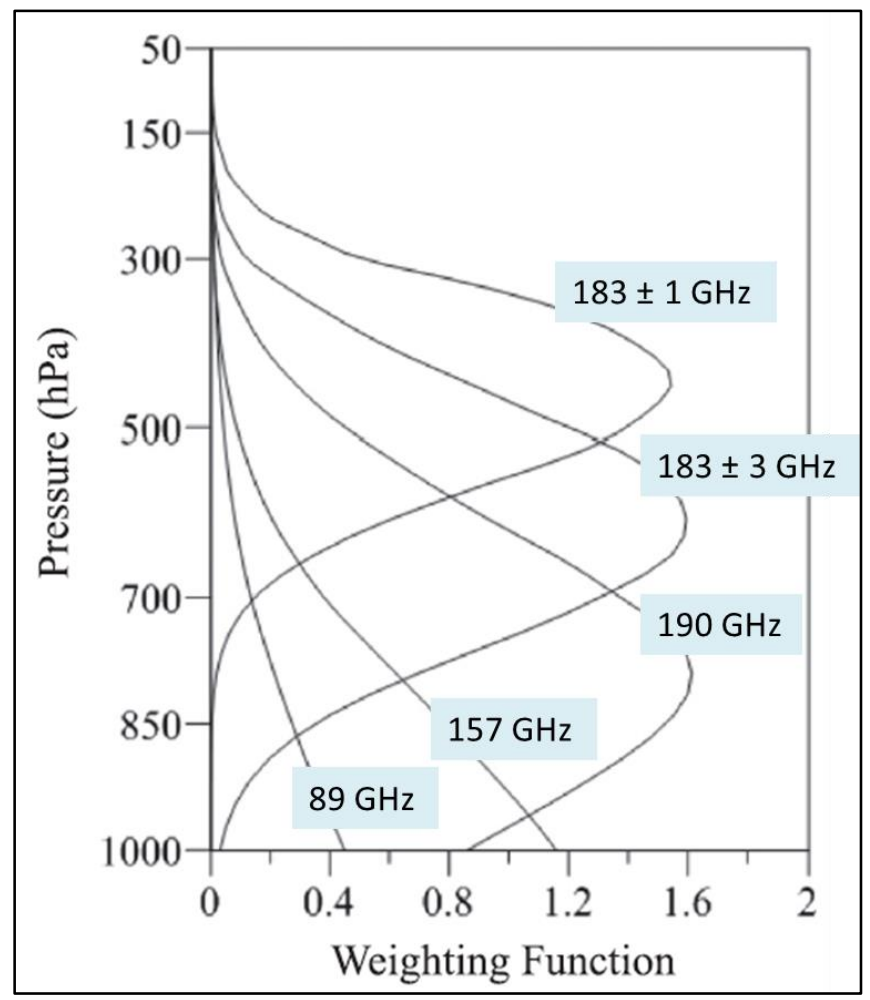

Figure 2. MHS sensor weighting functions after Zou et al. (2013). Similar channels sensitive to the water vapor profile are on the SSM/IS sensor.

and the background or climatology information used in the retrieval. The retrieval must untangle the weighting function overlap shown in Fig. 2 to arrive at a moisture profile of the atmosphere. Layer retrievals are best estimates of accounting for weighting function overlap effects within the retrieval data assimilation procedures. Because of the weighting function overlap, retrievals from adjacent vertical levels are highly correlated. High impact of the observations in the retrieval process is desirable, but to constrain the problem, a priori information about the atmosphere must be used. Although an arbitrary number of levels can be selected to be retrieved, only a few pieces of independent information are available from the five channels on MHS. The MIRS system outputs 100 levels of temperature and moisture, but only four independent basis functions are used for moisture (Boukabara et al. 2011), so that is the maximum number of independent levels of water vapor. The AIRS retrieval reports a degree-of-freedom field representing the amount of independent information, and it is typically between four and six.

Uncertainty from reported validation of the AIRS and MIRS retrievals and the amount of independent vertical information they contain is given in Table 3 . 
Table 3. Error characteristics and vertical resolution of AIRS and MIRS soundings.

\begin{tabular}{|c|c|c|}
\hline & AIRS V6 & MIRS \\
\hline Number of Reported Water Vapor Levels & 12 & 100 \\
\hline $\begin{array}{l}\text { Number of Independent Water Vapor Levels } \\
\text { Retrieved }\end{array}$ & Varies from 3 to 6 & No more than 4 \\
\hline Uncertainty & $\begin{array}{l}15 \% \text { of missing ratio in } 2-\mathrm{km} \text { layers from } \\
\text { surface to tropopause (Olsen et al. 2013) }\end{array}$ & $\begin{array}{l}15-20 \% \text { at } 950 \mathrm{hPa} ; 25-40 \% \text { at } 800 \mathrm{hPa} \\
\text { Uncertainty over land is about } 10-20 \% \text { higher } \\
\text { than over ocean at } 950 \text { and } 800 \mathrm{hPa} \text { (Boukabara } \\
\text { et al } 2000 \text {, Table V) } \\
\text { Reale et al (2009, Fig. 9) indicated seasonally } \\
\text { varying } 10-20 \% \text { Metop-A mixing ratio error } \\
\text { versus radiosondes at } 700 \mathrm{hPa}\end{array}$ \\
\hline
\end{tabular}

The AIRS moisture product is well-validated and is described as validation status 3 (Olsen 2013). AIRS water vapor product accuracy has been assessed, and the uncertainties in the product well established via independent measurements in a systematic and statistically robust way representing global conditions. AIRS global water vapor errors average $15 \%$ over 2$\mathrm{km}$ layers in the tropopause. The MIRS system is newer than AIRS and did not have a dedicated validation campaign. The MIRS uncertainty summary in Table 3 is based on a comparison with the GFS and European Centre for Medium-Range Weather Forecasts (ECMWF) analyses and radiosondes. Uncertainty (root sum square of standard deviation and bias) is between 15-40\% from 950 to $300 \mathrm{hPa}$. Uncertainty over land is $10-20 \%$ higher than over ocean at 950 and $800 \mathrm{hPa}$.

The NOAA Products Validation System (NPROVS; Reale et al. 2012) collocates radiosondes with a variety of satellite sounding retrievals to track performance through time. It is critical to continuously assess the performance of satellite soundings as sensor calibration may drift or channels on the sensor may fail. Reale et al. (2012, their Fig. 8) compared MIRS from Metop-A and AIRS soundings from the summer of 2010 and found that MIRS water vapor errors exceed that of AIRS. A comparison from 2009-2010 by Reale et al. (2012) at $700 \mathrm{hPa}$ shows MIRS MetopA uncertainty was near $40 \%$, with higher values in the winter.

The blended LWV products, similar to the blended TPW, are designed to be used as imagery products in animations. This provides implicit quality control because the human eye integrates the changing scenes and can track continuity of moisture structures and meteorological reasonableness to rapidly determine if the product is representative of the atmosphere. Blended products allow this type of quality inspection, which is very difficult with single sensor polarorbiting satellite products.

\section{Construction of blended layered water vapor products}

\section{a. Selection of spatial, temporal, and vertical resolution}

The purpose of this study was to create and demonstrate a product useful to forecasters; therefore, the number and spacing of vertical layers chosen to represent the troposphere needed to be manageable for a busy forecaster. In the data chosen for this study, AIRS has 12 layers available (when the surface pressure is greater than $1000 \mathrm{hPa}$ ) from the surface to $300 \mathrm{hPa}$, whereas MIRS has 100 highly correlated temperature and moisture levels. In the end, a total of four layers were chosen to reveal key vertical structure without overwhelming the forecaster with many layers. The choice of four layers also aligns with the amount of vertical information in the soundings as satellite soundings, unlike radiosondes, represent broad layers of the atmosphere. The layers chosen were surface to $850 \mathrm{hPa}, 850-700 \mathrm{hPa}, 700-500 \mathrm{hPa}$ and $500-300 \mathrm{hPa}$. If the surface pressure was $<850$ $\mathrm{hPa}$, the first layer is surface- $700 \mathrm{hPa}$. LPW is defined as the integral of the mixing ratio $q$ profile through a pressure layer, divided by gravity:

$L P W=\int_{p_{\text {top }}}^{p_{\text {bottom }}} q \frac{d p}{g}$

From Eq. (1), it is apparent that LPW is directly proportional to the layer-mean mixing ratio for a constant upper and lower layer pressure. Like TPW, 
LPW is commonly expressed by forecasters in millimeters or inches.

Blended LPW and LRH are produced every $3 \mathrm{~h}$ with blend times of 00, 03, 06, 09, 12, 15, 18, and 21 UTC. Currently, time weighting is not applied, only the most recent observation at each grid box is displayed, and the latency of the blended LWV product is about 45 minutes after the blend time. Blended retrievals within a file are from $2-10 \mathrm{~h}$ prior to the blend time with the majority of the retrievals within $4 \mathrm{~h}$ of the blend time. Data $12 \mathrm{~h}$ or more from the blend time are not used in the blended LPW and LRH products. These conditions were chosen to allow most of the scene to refresh every $3 \mathrm{~h}$ and to persist older data for visual continuity rather than having regions flicker on and off with missing data, which is very distracting for a forecaster viewing an animation.

The retrievals are mapped onto a near-global $\left(71^{\circ} \mathrm{N}\right.$ to $\left.71^{\circ} \mathrm{S}\right) 16-\mathrm{km}$ resolution (at the equator) Mercator projection, which consists of 1437 rows and 2500 columns. This is higher resolution than the satellites used in this study and near the resolution of the Metop-B retrievals that are being distributed in 2014. The use of a 16-km grid does not increase the product resolution when derived from $48-\mathrm{km}$ or greater resolution soundings because the soundings are repeated over multiple grid boxes. This grid matches the blended TPW grid.

\section{b. Blending procedure}

Once the remapped granules are available, they are composited to overlay the most recent data using DPEAS. The individual scan line times are preserved within DPEAS to accomplish this task. If a missing scan line or retrieval occurs, older data are allowed to be overlaid. This is common with AIRS which has missing retrievals in regions of extensive clouds, so more recent AIRS retrievals may be interspersed with older MIRS retrievals. The output production at CIRA is in HDF-EOS format, with a new file produced every $3 \mathrm{~h}$. All files contain gridded four-layer LPW and LRH fields with satellite time and identification. MIRS quality control parameters and chi-squared value (convergence metric) are mapped as well.

To allow forecasters to easily identify artifacts and features significant to the forecast process, the final blended LPW and LRH product is not smoothed. Smoothing of the blended products only occurs during the remapping operation to allow for easier identification of unphysical artifacts that might trouble a forecaster. These are most likely to include boundaries between sensor swaths, rapid value changes over land in the two near-surface product layers due to poor emissivity and land surface temperature solutions, and retrieval gradients at coastlines. However, as the product matures, spatial or even temporal smoothing could be applied as in the NOAA blended TPW product where a 15-point binomial smoother is used. The blended LPW and LRH presented here is in a minimally processed form other than remapping so any artifacts can be detected and investigated.

\section{Examples of blended layered water vapor pro- ducts}

The blended LPW product at $850 \mathrm{hPa}$ and the corresponding satellite identification map for 1500 UTC 24 June 2013 are shown in Fig. 3. Five satellites are present within the scene and, in general, the blended LPW product is seamless between the different spacecraft. A band of low-level moisture is oriented east-west across the Pacific towards southern California and appears without any discontinuities as it is observed by NASA Aqua (AIRS), NOAA-18 and NOAA-19. The Intertropical Convergence Zone (ITCZ) is readily apparent across the different satellite swaths. A minor seam is noticeable just south of the Aleutian Islands between the Metop-A and AIRS swaths. Recall from Fig. 1 that these spacecraft are almost $4 \mathrm{~h}$ apart in coverage, and the seam is partly due to the difference in time. Finally, the blended LPW product appears more blocky over Canada because of the higher resolution of the Mercator projection grid further north.

A few examples of the blended product and comparison to other water vapor analysis tools are now presented.

\section{a. Comparison to GOES water vapor imagery}

A GOES-15 water vapor channel image and corresponding blended LPW image for $500-300 \mathrm{hPa}$ are shown for 1200 UTC 5 November 2014 in Fig. 4. Recall that the blended LPW product does not use the GOES water vapor channel in the retrieval, so these are independent comparisons. The same large-scale features generally agree in each image; the green arrows in Fig. 4 indicate selected points of correspondence, but there are some differences. The moist and cloudy regions in the GOES water vapor image correspond to blended LPW values between 2-5 


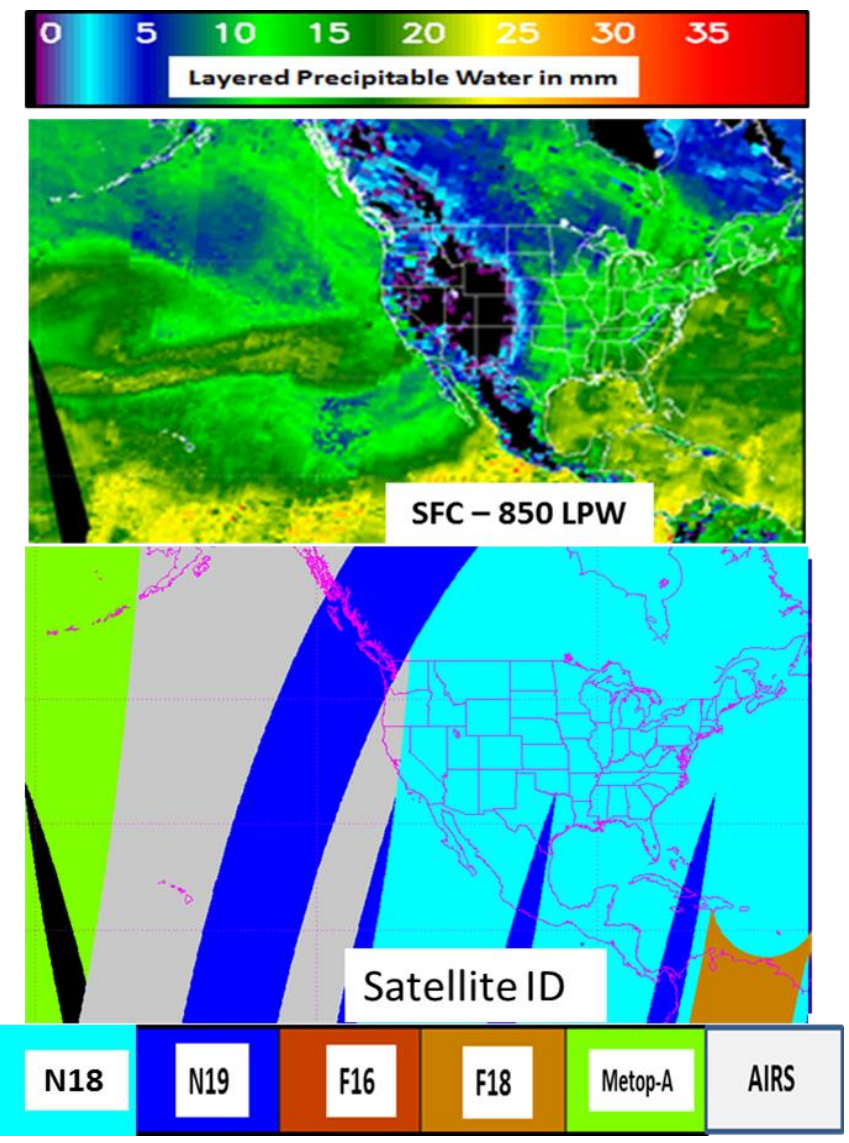

Figure 3. Surface-850-hPa LPW product and accompanying satellite identification map from 1500 UTC 24 June 2013 product. Black regions are missing data.

$\mathrm{mm}$, and this agrees with the expected response of the GOES water vapor imagery to the first $1-2 \mathrm{~mm}$ of water vapor (Jedlovec et al. 2000). In contrast, the blended LPW for 500-300 hPa lacks structure in very dry areas indicated in the GOES water vapor imagery, such as over the Pacific Ocean west of the Baja Peninsula, where blended LPW values are $1 \mathrm{~mm}$ or below. In this region, this indicates the GOES water vapor imagery is responding to moisture lower in the atmosphere. The vertical representation of GOES water vapor varies according to viewing angle and moisture profile (Wimmers and Moody 2001). Finally, the masking effect of rain and snow on the surface is apparent in the blended LPW product as missing areas colored black.

One of the goals of the blended LPW product is to provide better information on the vertical structure of moisture. Dry over moist air is often noted as important for severe weather forecasting as it can impact updraft velocities and the generation of supercell storm structure or derecho events (e.g., James and Markowski 2010). The complementary role
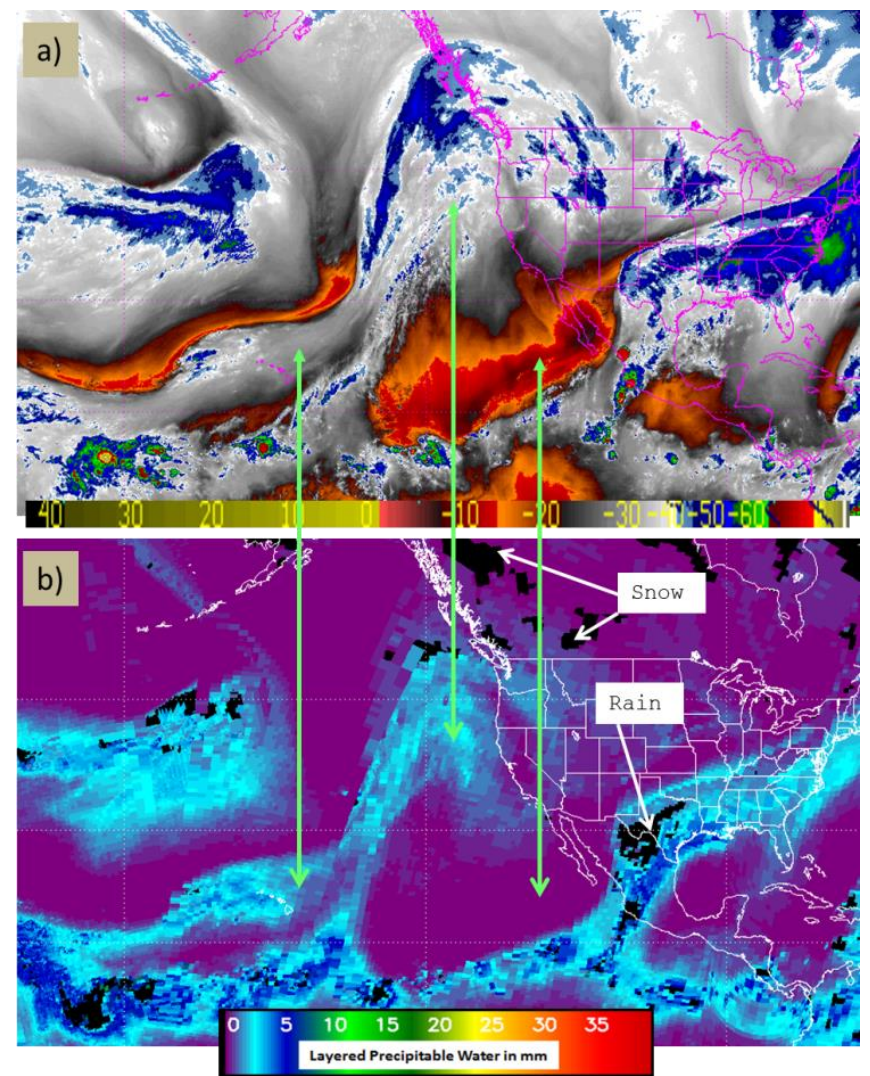

Figure 4. (a) GOES-15 6.7- $\mu \mathrm{m}$ water vapor image and (b) 500300-hPa blended LPW for 1200 UTC 5 November 2014. Missing regions because of rain or snow at the surface in the blended LPW are shown, and the green arrows indicate the same locations in each image.

of the blended LPW and traditional GOES water vapor imagery is illustrated in Fig. 5 during the morning of a multi-day severe weather outbreak. GOES-13 water vapor imagery (a) at 1100 UTC 28 April 2014 depicts very dry air over the western Gulf of Mexico, with deep convection into the Mississippi and Ohio River valleys. Over the western Gulf of Mexico, underneath the very dry air seen in the GOES water vapor image and the 700-500-hPa (b) blended LPW, abundant moisture exists from the surface to $700 \mathrm{hPa}$ (c, d). Behind the cold front over Oklahoma and Kansas, the blended LPW shows a deep layer of dry air is present that extends throughout the atmosphere. In particular, dry air in the GOES water vapor imagery over southwestern Missouri and northwestern Oklahoma is captured well by the blended LPW at all levels.

\section{b. September 2013 Colorado Front Range flood ani- mation}

Blended LPW is produced every $3 \mathrm{~h}$, and with the constellation of polar-orbiting satellites shown in Fig. 


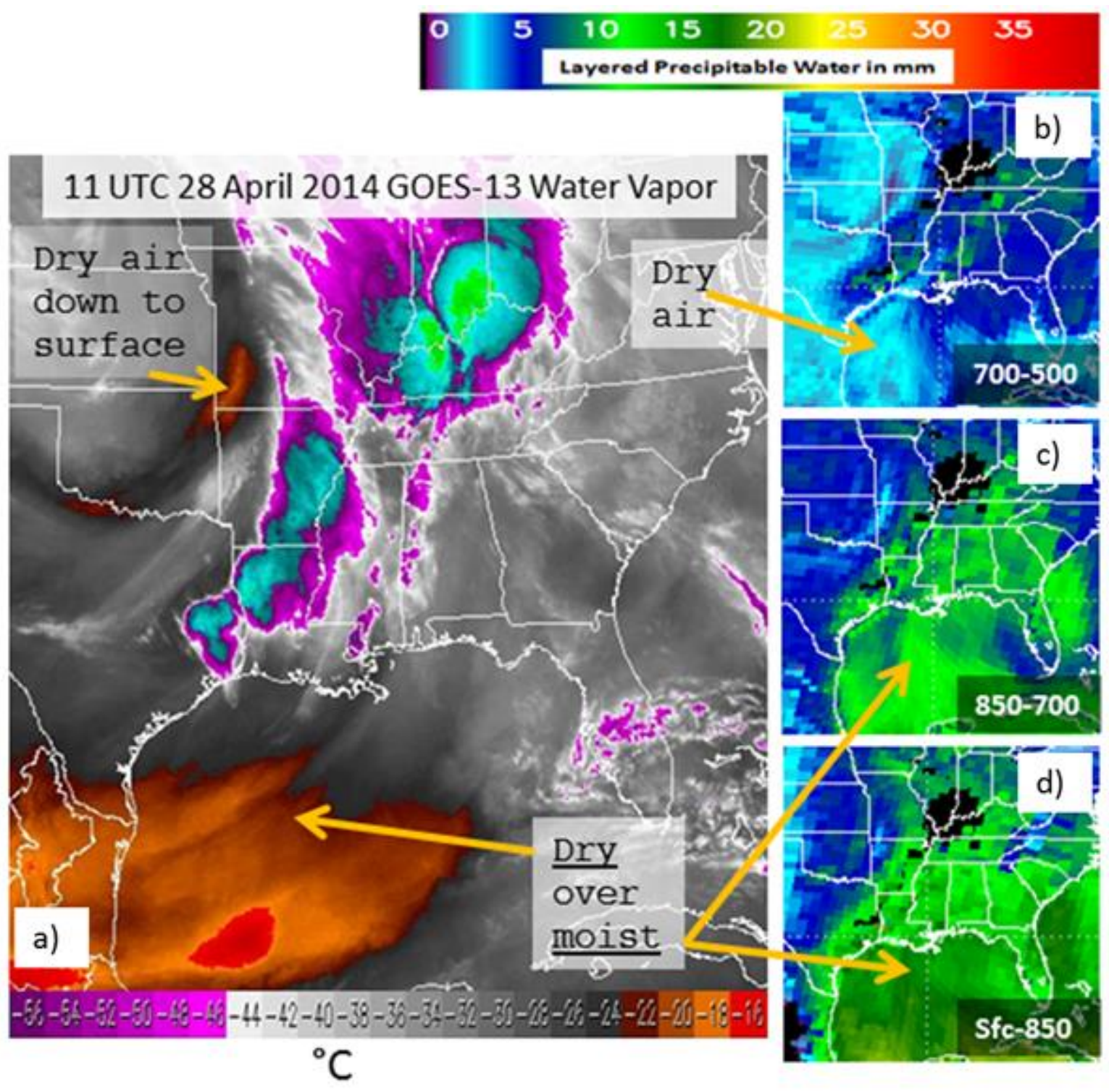

Figure 5. (a) GOES-13 water vapor channel image at 1100 UTC 28 April 2014 and (b-d) corresponding blended LPW for three layers. The GOES image has been provided by the NCAR Research Applications Laboratory.

1 , it is possible to see movement of moisture structures in an animation. Viewing animations of the product also functions as a means of quality control as discussed in Section 2. As an illustration of the power of viewing animated blended LPW, a loop before and during the flooding rains along the Colorado Front Range in September 2013 is shown in the animation in Fig. 6. The animation spans 0000 UTC 8 September 2013 to 2100 UTC 12 September 2013 and is updated every $3 \mathrm{~h}$. Although flooding occurred over a prolonged period, most of the flood-producing rainfall happened in the 48-h period between 1200 UTC 11 September and 1200 UTC 13 September 2014 (Schwartz, 2014). The sources of moisture at the different layers can be tracked, which is important in understanding the antecedent conditions and whether moisture above $700 \mathrm{hPa}$ will augment low-level moisture visible on surface observations and blended TPW. At 0000 UTC 9 September, a plume of mid and upper-level (i.e., above $700 \mathrm{hPa}$ ) moisture is in place from the ITCZ into Canada. This plume slowly moves eastward so that by 1200 UTC 9 September the moisture axis is over the mountains and eastern plains of Colorado. The high topography of the Rockies makes the surface- $850-\mathrm{hPa}$ layer challenging to use, but the deep moisture is visible in the LPW 850-700$\mathrm{hPa}$ layer over the western Gulf of Mexico and advects northward over the central Plains. In contrast, moisture 


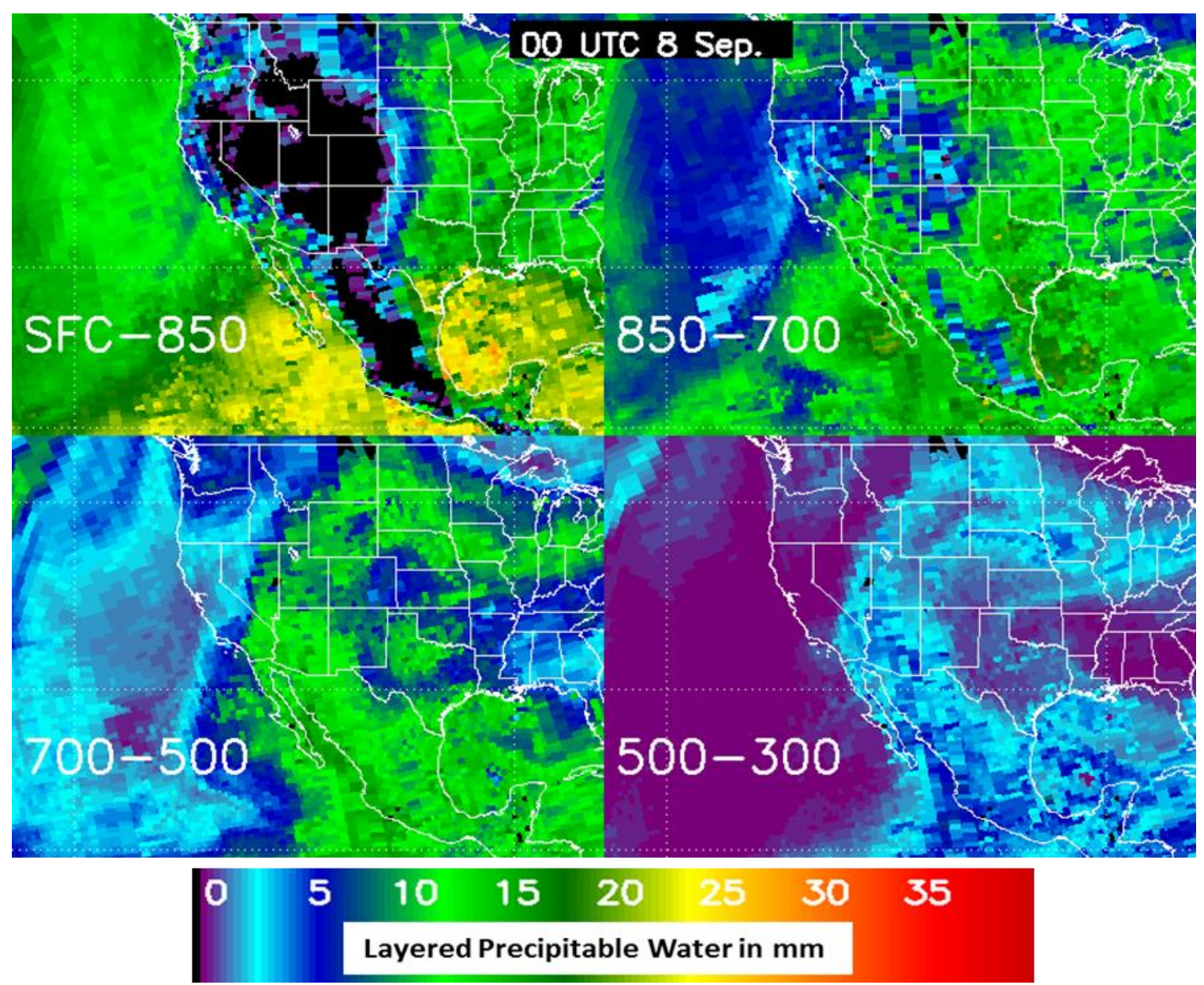

Figure 6. Four-panel animation of LPW before and during the historic flooding rains on the Colorado Front Range. Image shown is from 0000 UTC 10 September 2013, and the animation spans 0000 UTC 09 September 2013 to 2100 UTC 12 September 2013, updated every $3 \mathrm{~h}$. Hour (UTC) and date of blending shown in top center. Click image for an external animation.

above $700 \mathrm{hPa}$ is not as apparent over the Gulf during this time, as drying moves from east to west at upper levels. Tracking the amount and areal extent of LPW from these sources allows a forecaster to visualize whether water vapor supporting heavy precipitation continues to flow or if drying is beginning.

\section{c. Comparison to commonly used analysis tools}

On 4 November 2014 Hurricane Vance approached the Mexican coast as a category 2 hurricane. Shortly before landfall, strong wind shear weakened Vance to a tropical depression by 0900 UTC 5 November 2014. Vance brought copious amounts of tropical moisture to Mexico and across the Sierra Madre Mountains into Texas. The Del Rio and Corpus Christi, Texas, radiosondes measured TPW in the 99th percentile at 1200 UTC on 5 November 2014, with values of 39 and $49 \mathrm{~mm}$ respectively noted in the
National Environmental Satellite, Data, and Information Service (NESDIS) Satellite Analysis Branch (SAB) discussion. Widespread heavy rains occurred over east Texas, with over $50 \mathrm{~mm}$ of rainfall reported. The SAB issued two messages on the moisture from Vance and the heavy rainfall potential for Texas.

A comparison of the analysis tools listed in Table 1 with the LPW product and the layered relative humidity product illustrates the potential impact to operations suggested in Table 2. In Fig. 7, four radiosondes along the Mexican coast show a wide range of TPW, with values from $16 \mathrm{~mm}$ at $\mathrm{La} \mathrm{Paz}$ on the dry north side of the tropical moisture plume from Vance to $61 \mathrm{~mm}$ at Colonia Juancarrasco. The soundings at Guadalajara and Manzanillo are nearly saturated, although the Manzanillo sounding terminated prematurely at $575 \mathrm{hPa}$. These coastal 


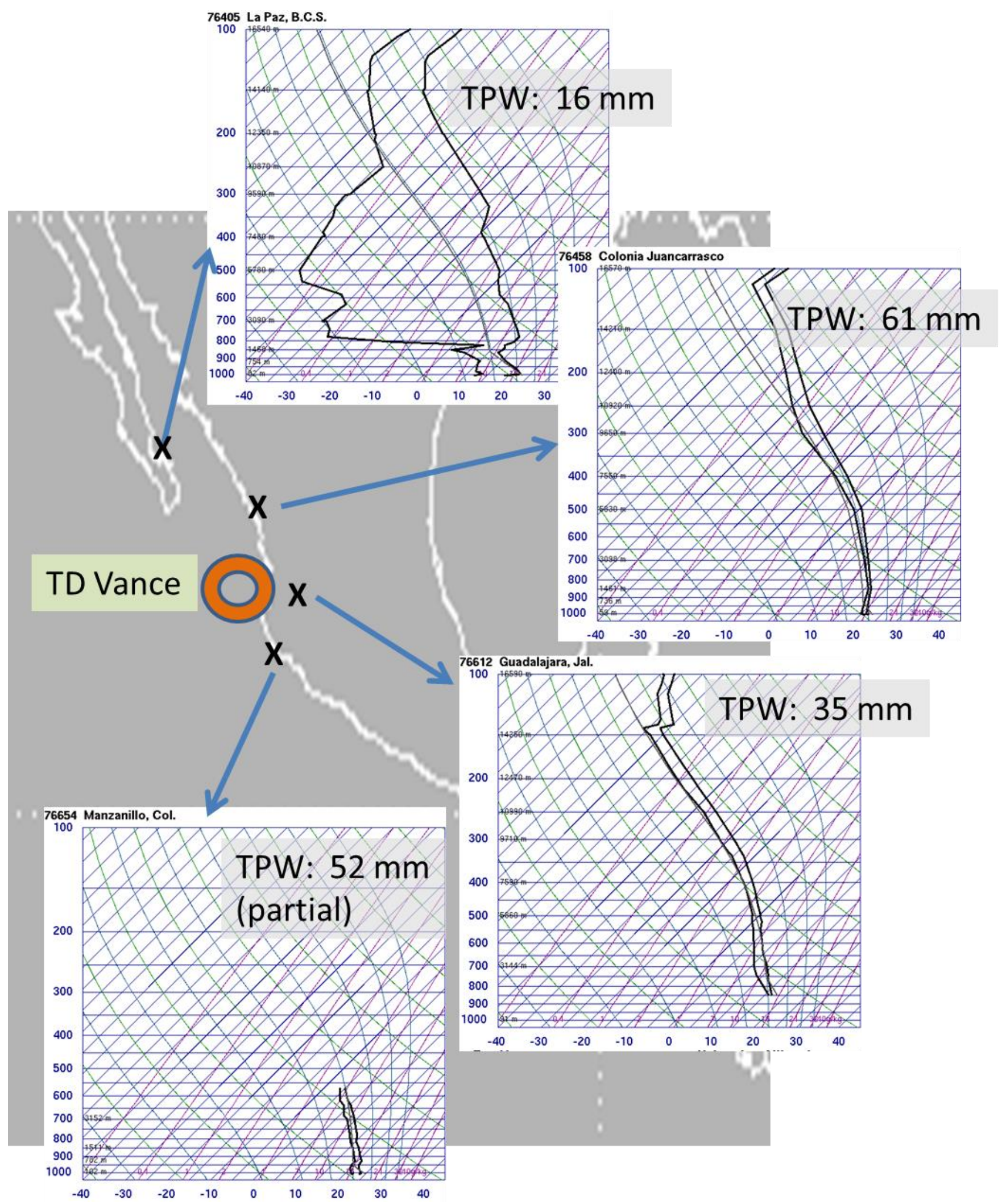

Figure 7. Location of La Paz, Colonia Juancarrasco, Guadalajara, and Manzanillo (failed at $575 \mathrm{hPa}$ ) radiosondes (black X's) near the Mexican coast at 1200 UTC 5 November 2014. The center of Tropical Depression Vance (orange circle) and total precipitable water are shown from each radiosonde. Soundings are from the University of Wyoming (weather.uwyo.edu/upperair). 
sondes capture the high moisture, but the placement of the transition along the coast from very dry upper levels at La Paz to the nearly saturated sounding at Colonia Juancarrasco cannot be determined from the radiosondes because of their coarse horizontal spatial resolution. The LPW maps at 1200 UTC 5 November 2014 for three levels are shown in Fig. 8, along with the GOES sounder retrievals (Lee et al. 2014) of LPW on three $\sigma$-coordinate layers. The blended LPW maps show the spatial structure and gradients that are not visible in the sonde or GOES sounder fields.

In Fig. 8, there is no direct correspondence because of the two different vertical coordinates, but low-, middle- and high-level moisture patterns can be visualized from each analysis. Two limitations of the GOES sounder product are apparent in Fig. 8: the lack of sensor scanning over the entire domain and the inability to perform retrievals because of clouds. A forecaster examining moisture flowing into Texas would have no data over the central coast of Mexico. In fact, there are only a few GOES sounder pixels over the state of Texas, in the panhandle region. In contrast, the blended LPW has more coverage over Texas at all levels, but no retrievals are available centered on the Big Bend region because of precipitation, which interferes with the MIRS retrievals. A tongue of moisture with amounts as high as $10 \mathrm{~mm}$ is apparent in the $850-700-\mathrm{hPa}$ blended LPW over the Gulf of Mexico from the Yucatan to the southern tip of Texas. In the GOES sounder, this band of enhanced moisture is obscured by clouds. Other distinctions between the blended LPW and the GOES sounder layered moisture are apparent. The blended LPW is lacking coverage over a large portion of the Rocky Mountains in the surface- $850-\mathrm{hPa}$ layer because of elevated topography, while the use of the $\sigma$ coordinate in the GOES sounder allows coverage in the mountains.

In order to visualize the three-dimensional data from the blended LPW soundings, a display of soundings plotted with the GOES water vapor image and blended TPW image as a background was created. The GOES-15 water vapor channel image from 1200 UTC 5 November 2014 centered on Mexico is displayed in Fig. 9a, and the same soundings are plotted on the operational blended TPW image in Fig. $9 \mathrm{~b}$, with the soundings representing the profile from the center point of the plotting box. This comparison provides context between cloud systems and upperlevel moisture from the water vapor image and blended LPW features. In Fig. 9a, the plume of tropical moisture associated with Vance, as discussed earlier, is visible in the water vapor image. The LPW profiles exhibit a few noteworthy features. First, they typically follow a decreasing profile, as the higher layers of the atmosphere are able to contain less and less moisture. Second, some profiles inland over Mexico only contain sounding information at the two upper layers, because of the mountains. A third feature noticed over the mountains in Mexico are occasional profiles that increase in LPW vertically; an example is just south of the Gulf of Tehuantepec. This is because of the lowest layer having only a thin layer of atmosphere to integrate before the $850-700-\mathrm{hPa}$ or 700-500-hPa layer begins.

The soundings plotted on the water vapor image in Fig. 9a go well beyond what information can be gleaned solely from the water vapor image. The very dry air near Baja indicated in the water vapor imagery by the dark orange colors near $-5^{\circ} \mathrm{C}$ are very close to the La Paz sounding shown in Fig. 7. The LPW values are near $0 \mathrm{~mm}$ in the 500-300-hPa layer here. Heading south from Baja along the green dashed line A-A' and inspecting the LPW soundings, we see moisture rapidly increase in the lowest layers, from near $10 \mathrm{~mm}$ to more than $20 \mathrm{~mm}$ in the surface- $850-\mathrm{hPa}$ layer. This low-level moisture is an ingredient for downstream heavy rainfall. Continuing south into the moisture plume, the $500-300-\mathrm{hPa}$ moisture begins to increase.

The blended TPW product as a background is shown in Fig. 9b. While blended TPW is a separate product from layered products shown here, blended TPW is currently partially derived from the integrated MIRS soundings, and a correlation (especially at the low layers) is expected. The blended TPW senses the high values of atmospheric moisture. Recall that the two radiosondes in Texas were at the 99th percentile for November, and nearly all of the blended LPW soundings in the red or purple $(>50 \mathrm{~mm})$ region of blended TPW have surface- 850 -hPa values $\geq 20 \mathrm{~mm}$.

A comparison of the blended LRH with the GFS relative humidity analysis over a larger domain at the same time (1200 UTC 5 November 2014) is shown in Fig. 10. If two analyses agree when arrived at by different means - selected radiance assimilation for the GFS versus the AIRS or MIRS retrievals for blended LRH - the forecaster has more confidence in future model forecasts from the same run in much the same way as model-to-model agreement or disagreement is factored into a forecast decision. In order to plot fields currently available to forecasters, in Fig. 10 the GFS relative humidity at the $400,600,800$ and $925 \mathrm{hPa}$ 

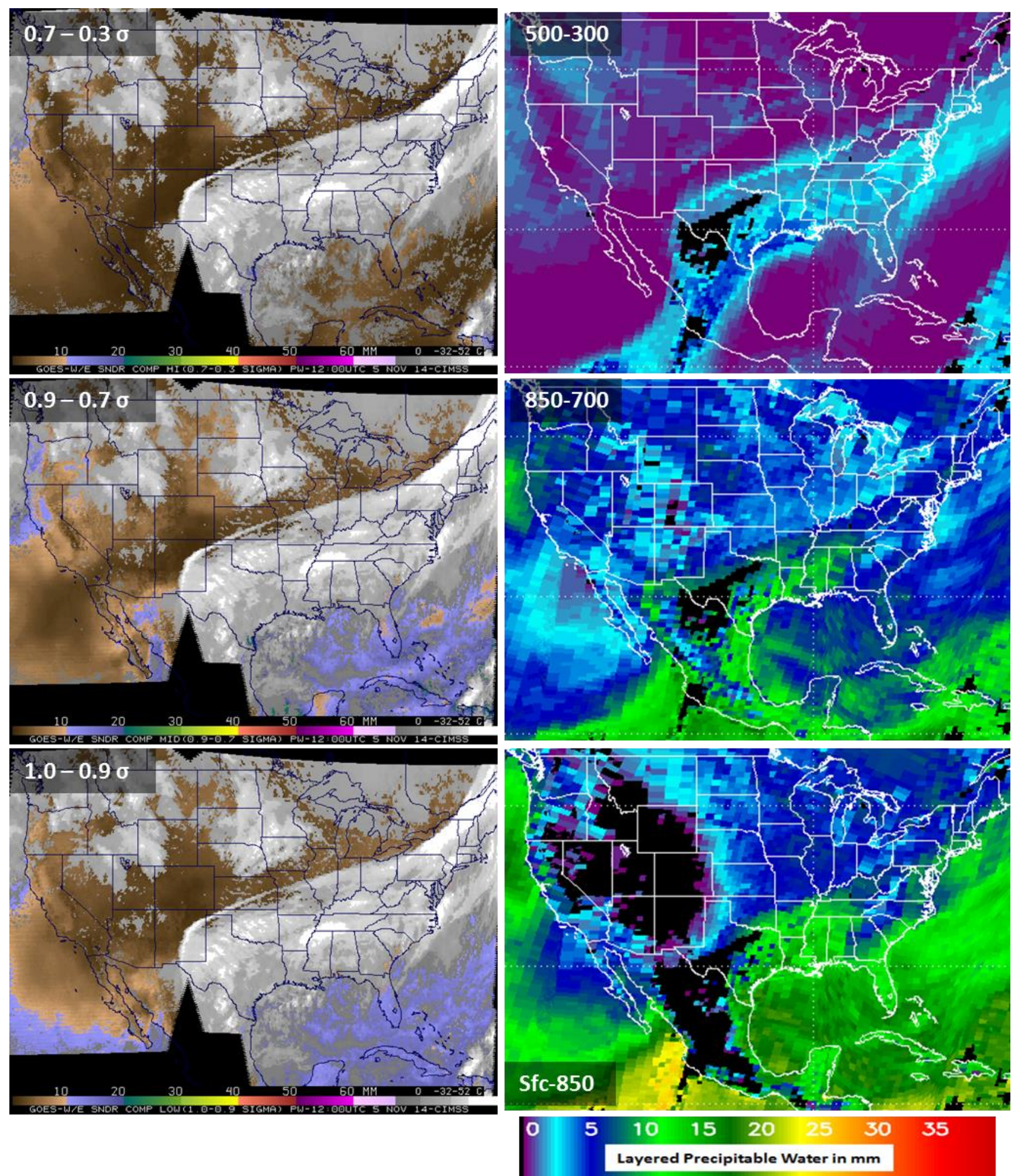

Figure 8. GOES sounder-derived layer precipitable water vapor for three sigma layers (left column) and blended LPW (right column) for three pressure layers, which correspond to 1200 UTC 5 November 2014. The blended LPW swaths are within an hour of 1200 UTC. GOES

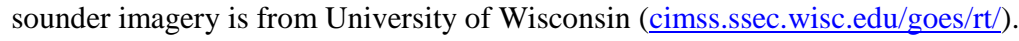

levels are plotted with the four blended relative humidity layers. These points are roughly at the midpoint of the layers, so good correlation is expected. This plot allows a forecaster to quickly view where the 

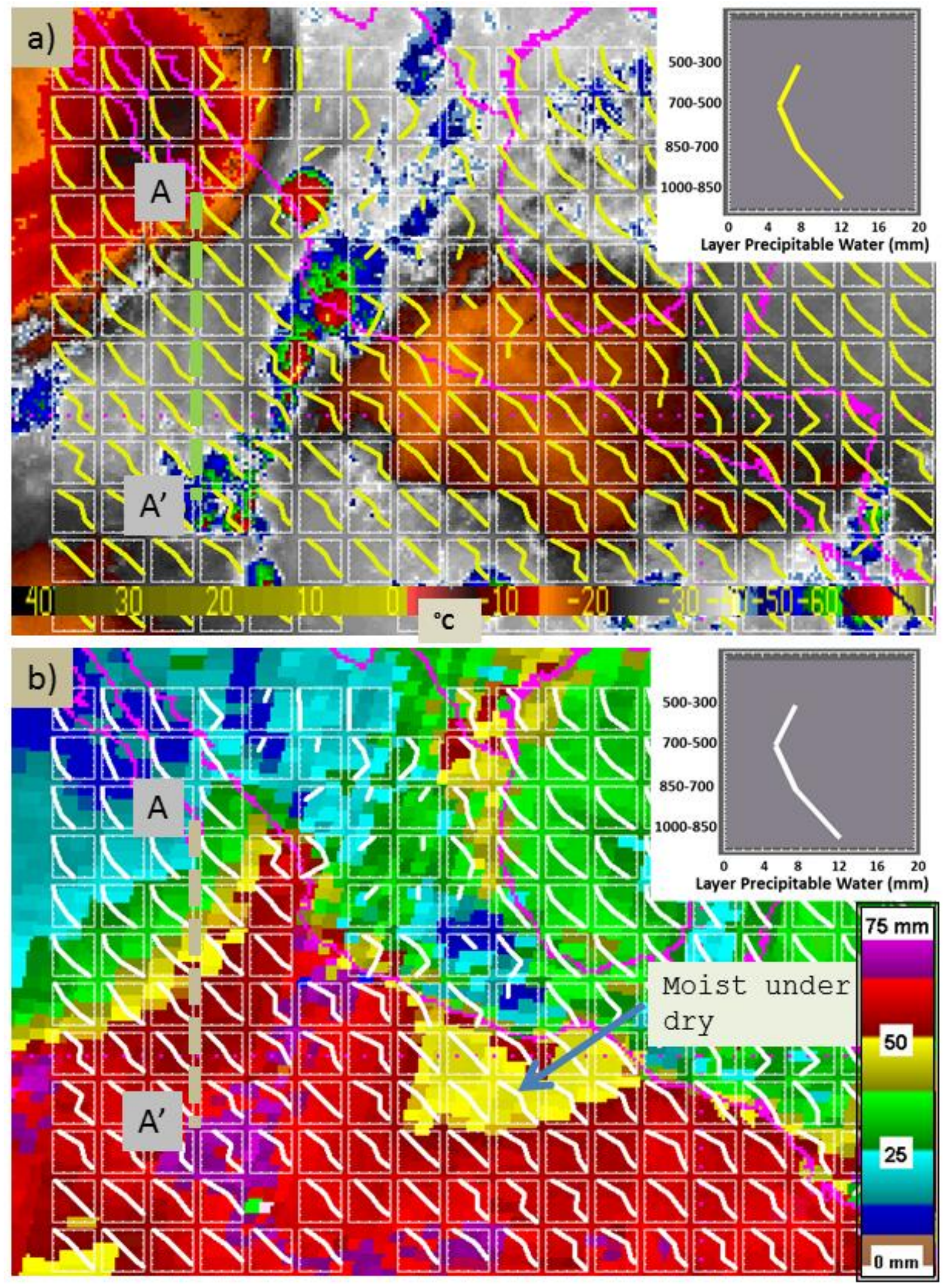

Figure 9. (a) GOES-15 water vapor image with blended LPW profiles (in yellow) from 1200 UTC 5 November 2014 and (b) operational blended TPW product with blended LPW profiles (in white). A cross section along line A-A' and enlarged sounding plotted in the inset box are shown. The plotted soundings represent the sounding at the center of the plotting box. 


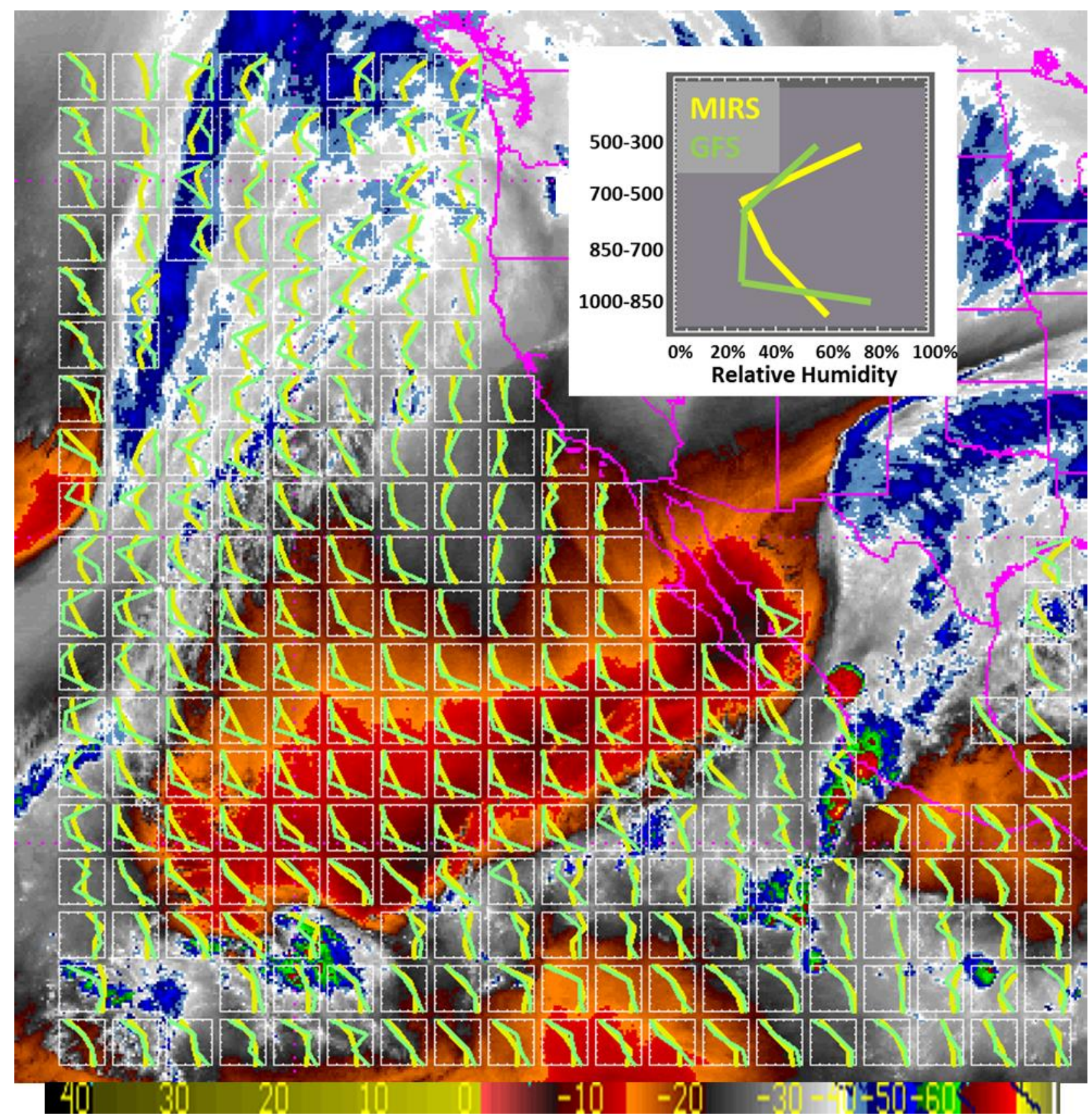

Figure 10. GOES-15 water vapor image with blended LRH (yellow) and GFS 0-h analysis (green) profiles at 1200 UTC 5 November 2014. The GFS profiles are taken from 400, 600, 800, and $925 \mathrm{hPa}$ while the LRH profiles are for the 500-300-, 700$500-, 850-700-$, and surface to 850 -hPa layers. An enlarged sounding plotted in the inset box is shown, and the plotted soundings represent the sounding at the center of the plotting box.

model analysis and the blended product are similar and different. Overall, the blended LRH profiles and the GFS profiles are similar. In some areas, such as the ITCZ, the soundings are nearly coincident. In the dry subtropical high region west of Baja, the GFS profile commonly has higher relative humidity at the $925 \mathrm{hPa}$ level versus the surface-850-hPa layer in blended $\mathrm{LRH}$, with the largest disagreement occurring in the frontal band off the California and Oregon coast. Here, the GFS produces some nearly saturated profiles while the blended LRH has saturation in the upper layers but values of $60-80 \%$ in the lower layers. Another difference between the soundings is that the GFS profiles often exhibit sharper gradients with height. For example, a few GFS grid boxes just offshore in the moisture plume approaching Baja associated with 
Tropical Depression Vance exhibit negative-positivenegative slopes from 925 to $400 \mathrm{hPa}$. It is possible additional smoothing from computing layer means from GFS would reduce this behavior. The blended LRH, owing to the reasons discussed in Section 2, does not exhibit as sharp vertical gradients.

\section{Conclusions}

A near real-time, four-layer water vapor product using retrievals from five polar-orbiting satellites (NOAA-18 and -19; DMSP F-18; Metop-A; and NASA Aqua) has been created. The product consists of mapped LPW and LRH on a global grid with satellite identification and related metadata. The use of multiple satellite inputs at different local times and product generation every $3 \mathrm{~h}$ allows visualization of the flow of water vapor in layers. The product has advantages while complementing the depiction of water vapor for forecasters currently obtained from radiosondes, GOES water vapor imagery, blended TPW imagery, and model analysis fields. Sounding coverage over the data-sparse oceans in cloudy conditions is a key forecast analysis benefit of the new product. The blended LPW and LRH depict moisture and saturation in these four layers: surface $-850-\mathrm{hPa}$, 850-700-hPa, 700-500-hPa and 500-300-hPa. While GOES water vapor imagery tracks upper-level moisture and blended TPW responds mostly to lowlevel moisture, the blended LWV fields sample the middle layer of the atmosphere, which is not wellrepresented by these tools. The blended LWV product is independent of numerical weather prediction models and uses all of the satellite data available from each sensor, in contrast to model data assimilation schemes that may thin data or reject cloudy radiances. Examples of the utility of LPW and LRH were shown for a severe weather event in 2013, the Colorado Front Range floods in 2013, and Tropical Depression Vance in 2014.

The blended LPW and LRH products are produced with a minimal level of post-processing for this first demonstration. Additional image processing techniques, such as histogram matching (Kidder and Jones 2007) and spatial smoothing as applied to the operational NOAA blended TPW product, could be used in the future to further reduce inter-satellite differences. The goal of any product modification is always to enhance the depiction of true meteorological features that forecasters can meaningfully interpret while suppressing the artifacts caused by different

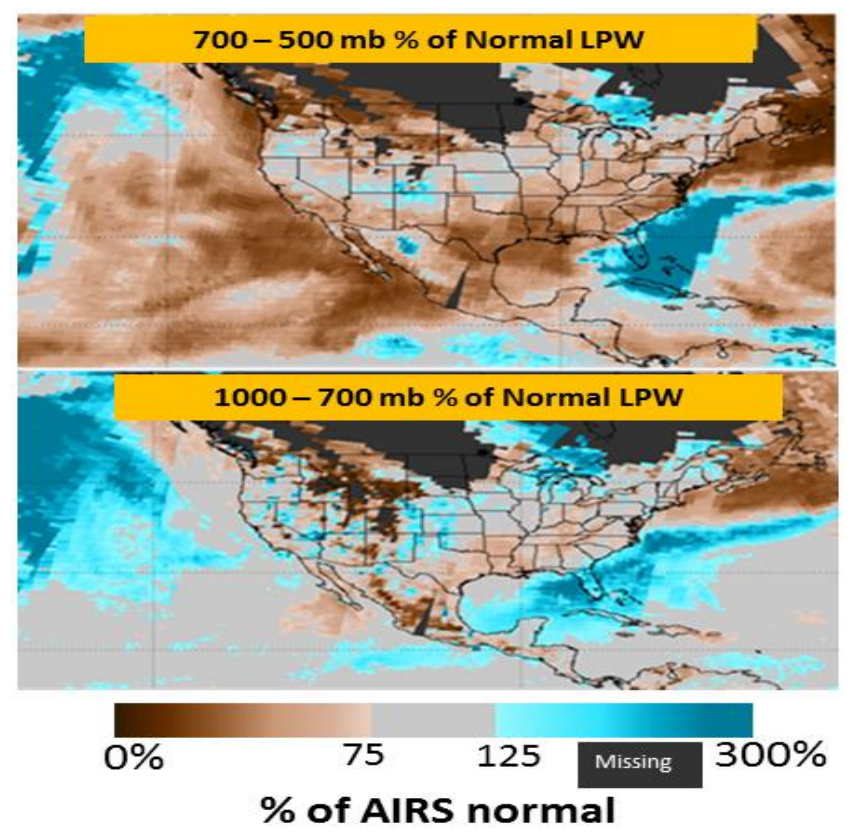

Figure 11. LPW percent of normal (\%) prototype product at 1800 UTC 22 April 2013. Values between 75 and 125\% of normal are shaded in light grey, and dark grey areas are missing because of snow cover.

sensors, situationally dependent retrieval biases, and varying spatial resolution.

Future innovations for the blended LPW product could follow the path of the NOAA operational blended TPW as additional spacecraft, such as SuomiNPP and Metop-B, with retrievals at higher spatial resolution could be added. Anomaly products could be created to aid forecasters in understanding extreme moist and dry intrusions, as LPW anomalies likely are well correlated with cloud vertical structure, as was found for blended TPW anomalies (Forsythe et al. 2012). A prototype LPW anomaly product at two levels is shown in Fig. 11. The normal for this prototype case is a monthly climatology of AIRS V5 Level 3 retrievals from 2003-2008. Because the AIRS climatology is affected by biases in sampling due to avoidance of clouds (Yue et al. 2013) and the MIRS retrievals are possible across a wider range of cloud opacity, the normal for this prototype case is a monthly climatology of AIRS V5 Level 3 retrievals from 2003-2008. An LPW anomaly product must be further evaluated to reduce differences between the weather and climatology water vapor fields. Usage of other climatology fields with longer time records could be fruitful, such as from the NASA Water Vapor Project dataset (Vonder Haar et al. 2012), which covers 1988-2009. In the future, the proposed NASA 
Precipitation and All-weather Temperature and Humidity geostationary microwave mission (National Research Council 2012) would be a very powerful addition for the LWV products. Composited polar orbiter data are the closest current observational proxy for a geostationary passive microwave sensor.

Acknowledgments. This research was supported at CIRA by NASA Grant NNX11AL77G. Sheldon Kusselson of the NESDIS Satellite Analysis Branch provided thoughtful feedback. Eric Fetzer and Evan Fishbein of the NASA Jet Propulsion Laboratory AIRS team provided useful comments on the product.

\section{REFERENCES}

Boukabara, S.-A., and Coauthors, 2011: MiRS: An allweather 1DVAR satellite data assimilation and retrieval system. IEEE Trans. Geosci. Remote Sens., 49, 32493272, CrossRef.

Dang, H. V. T, Lambrigtsen, B., Manning, E., Eds., 2012: AIRS/AMSU/HSB Version 6 Level 2 Performance and Test Report. NASA Jet Propulsion Laboratory, Pasadena, CA, 197 pp. [Available online at disc.sci.gsfc.nasa.gov/AIRS/documentation/v6_docs/v6 releasedocs-1/V6_L2_Performance_and_Test_Report.pdf.]

Forsythe, J. M., J. B. Dodson, P. T. Partain, S. Q. Kidder, and T. H. Vonder Haar, 2012: How total precipitable water vapor anomalies relate to cloud vertical structure. J. Hydrometeor., 13, 709-721, CrossRef.

James, R. P., and P. M. Markowski, 2010: A numerical investigation of the effects of dry air aloft on deep convection. Mon. Wea. Rev., 138, 140-161, CrossRef.

Jedlovec, G. J., J. A. Lerner, and R. J. Atkinson, 2000: A satellite-derived upper-tropospheric water vapor transport index for climate studies. J. Appl. Meteor., 39, 15-41, CrossRef.

Jones, A. S., and T. H. Vonder Haar, 2002: A dynamic parallel data-computing environment for cross-sensor satellite data merger and scientific analysis. J. Atmos. Oceanic Technol., 19, 1307-1317, CrossRef.

Jones, T. A., and D. J. Stensrud, 2012: Assimilating AIRS temperature and mixing ratio profiles using an ensemble Kalman filter approach for convective-scale forecasts. Wea. Forecasting, 27, 541-564, CrossRef.

Kidder, S. Q., and T. H. Vonder Haar, 1995: Satellite Meteorology: An Introduction, Academic Press, 466 pp. , and A. S. Jones, 2007: A blended satellite total precipitable water product for operational forecasting. J. Atmos. Oceanic Technol. 24, 74-81, CrossRef.

Lee, Y.-K., Z. Li, J. Li, and T. J. Schmit, 2014: Evaluation of the GOES-R ABI LAP retrieval algorithm using the GOES-13 sounder. J. Atmos. Oceanic Technol., 31, 319, CrossRef.
Li, J., T. J. Schmit, X. Jin, and G. Martin, 2010: GOES-R Advanced Baseline Imager (ABI) algorithm theoretical basis document for legacy atmospheric moisture profile, legacy atmospheric temperature profile, total precipitable water, and derived atmospheric stability indices: Version 2.0. NOAA/NESDIS/STAR, $106 \mathrm{pp}$. [Available online at www.goes-r.gov/products/ATBDs/ baseline/Sounding_LAP_v2.0_no_color.pdf.]

National Research Council, 2012: Earth Science and Applications from Space: A Midterm Assessment of NASA's Implementation of the Decadal Survey. Committee on the Assessment of NASA's Earth Science Program, Space Studies Board, Division on Engineering and Physical Sciences, The National Academies Press, Washington, DC, 124 pp.

Nehrkorn, T., B. Woods, T. Auligné, and R. N. Hoffman, 2014: Application of feature calibration and alignment to high-resolution analysis: Examples using observations sensitive to cloud and water vapor. Mon. Wea. Rev., 142, 686-702, CrossRef.

Olsen, E. T., Ed., 2013: AIRS/AMSU/HSB Version 6 Level 2 Product User Guide. NASA Jet Propulsion Laboratory, Pasadena, CA, $139 \mathrm{pp}$. [Available online at disc.sci.gsfc.nasa.gov/AIRS/documentation/v6_docs/v6 releasedocs-1/V6_L2_Product_User_Guide.pdf.]

Rodgers, C. D., 2000: Inverse methods for atmospheric sounding: theory and practice. World Scientific Publishing Co. Pte. Ltd., 238 pp.

Schwartz, C. S., 2014: Reproducing the September 2013 record-breaking rainfall over the Colorado Front Range with high-resolution WRF forecasts. Wea. Forecasting, 29, 393-402, CrossRef.

Vonder Haar, T. H., J. L. Bytheway, and J. M. Forsythe, 2012: Weather and climate analyses using improved global water vapor observations. Geophys. Res. Lett., 39, 1-6, CrossRef.

Wimmers, A. J., and J. L. Moody, 2001: A fixed-layer estimation of upper tropospheric specific humidity from the GOES water vapor channel: Parameterization and validation of the altered brightness temperature product. J. Geophys. Res., 106, 17115-17132, CrossRef.

Wu, L., and Coauthors, 2012: Relationship of environmental relative humidity with North Atlantic tropical cyclone intensity and intensification rate. Geophys. Res. Lett., 39, 1-8, CrossRef.

Yue, Q., E. J. Fetzer, B. H. Kahn, S. Wong, G. Manipon, A. Guillaume, and B. Wilson, 2013: Cloud-statedependent sampling in AIRS observations based on CloudSat cloud classification. J. Climate, 26, 83578377, CrossRef.

Zou, X., Z. Qin, and F. Weng, 2013: Improved quantitative precipitation forecasts by MHS radiance data assimilation with a newly added cloud detection algorithm. Mon. Wea. Rev., 141, 3203-3221, CrossRef. 